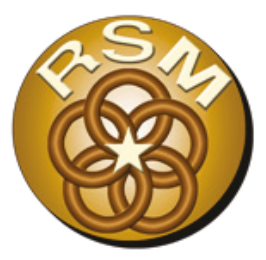

\title{
Hawaii Regional Sediment Management: West Maui Region; Nearshore Sedimentation at Honokowai Stream
}

\author{
by Jessica H. Podoski, Lauren Molina, Zeki Demirbilek,
} and Lihwa Lin

PURPOSE: This study was conducted as a conceptual effort, at an island scale as opposed to the extensive watershed scale within the continental United States, to apply the Coastal Modeling System (CMS) and the Particle Tracing Model (PTM) numerical models to investigate the transport and fate of inland sediment inputs to the nearshore littoral environment. In tropical islands with high elevations, terrestrial runoff can pose a severe threat to the health of surrounding coral reefs (Pinniak 2004). Because inland sediment input to the nearshore littoral environment is a coral reef stressor, the CMS and PTM were applied to better understand the circulation patterns along the coast that influence the transport and fate of the Honokowai stream sediment inputs within the nearshore littoral environment of the West Maui, HI, region. Further comprehensive three-dimensional (3D) modeling of the region is recommended to quantify cohesive sediment transport, temperature and salinity effects, and pre- and post-storm sedimentation data at coral reefs.

BACKGROUND: Regional Sediment Management (RSM) refers to the effective use of littoral, estuarine, and riverine sediment resources in an environmentally sensitive and economically efficient manner. RSM was officially implemented at the U.S. Army Corps of Engineers (USACE), Honolulu District (POH), in February 2004. The POH overall RSM strategy is to investigate RSM opportunities along all regions in Hawaii and the U.S. Pacific Territories. Conceptual regional sediment budgets have been developed in various regions throughout the islands to gain a general understanding of the control that morphology and coastal processes have on sediment pathways and transport volumes.

The West Maui region, located on the Island of Maui (Figure 1), incorporates a thin coastal margin backed by steep mountainous terrain that has been vastly altered by agricultural and urban development. Inland sediment makes its way from the five watersheds (Wahikuli, Honokowai, Kahana, Honokahua, and Honolua) in the West Maui RSM study area to the coastal waters via streams and drainages (Figure 1). The federally authorized West Maui Watershed Study is included within the larger West Maui "Ridge to Reef" (R2R) Initiative, which engages various federal, state, and county agencies in the implementation of a strategy to reduce the threats of landbased pollution to coral reefs in West Maui. Collaboration and coordination of Hawaii RSM investigations in the West Maui region, and the work being conducted through the West Maui R2R Initiative, are being utilized to enhance the utility of the products being developed. 


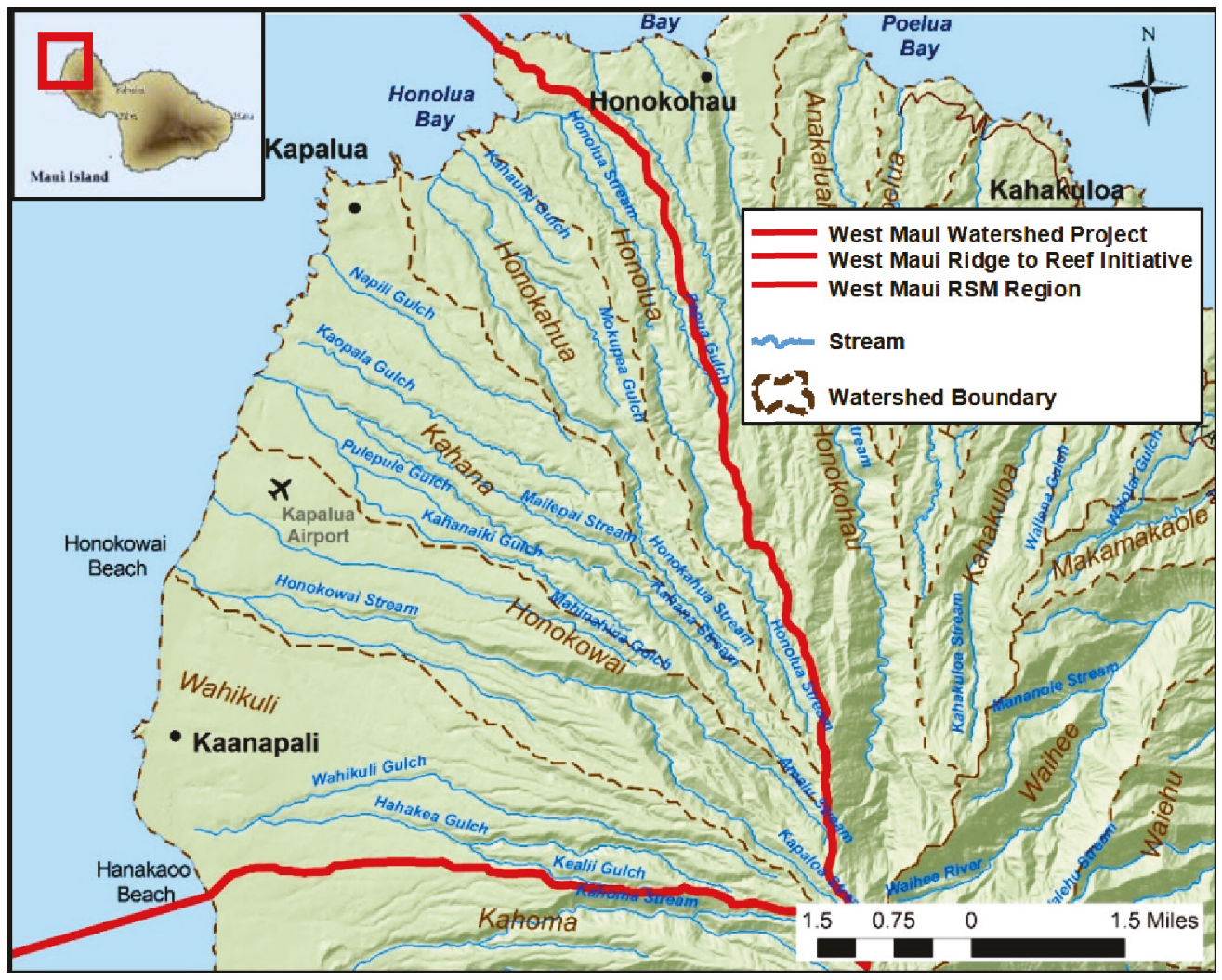

Figure 1. Location map of the West Maui Watershed Project, R2R Initiative, RSM region, and watershed boundaries and streams.

APPROACH: CMS numerical models CMS-Wave and CMS-Flow (Demirbilek and Rosati 2011; Lin et al. 2011; Sanchez et al. 2011a,b) were implemented along the West Maui region in Fiscal Year 2014 (FY14) as part of Hawaii RSM to simulate wave transformation and water circulation within the region. These investigations focused on coastal sediments and are summarized in Podoski et al. (2016). Prevailing wind (trade wind) and predominant wave (northwest and south) conditions were simulated in steering mode to capture the interdependence of waves and currents. In addition, qualitative analysis using the PTM (MacDonald et al. 2006) identified dominant sediment pathways for fine terrestrial sediments. The previous simulations for this area, in addition to stream flow and sedimentation data developed as part of the R2R Initiative, were leveraged to evaluate the pathways of terrigenous sediments entering the nearshore from streams and drainages in the West Maui region.

RIDGE TO REEF (R2R) EXISTING INFORMATION: The West Maui R2R and RSM region (Figure 1) includes five watersheds. In 2011, the U.S. Coral Reef Task Force added a priority watershed partnership designation to the Wahikuli and Honokōwai watersheds, the two southernmost in the region, which include the coastline from Kahana Beach to Hanako'o Beach. The coral reef at the base of the Honokōwai watershed is designated as one of two priority coral reefs in the United States by the National Oceanographic and Atmospheric Administration (NOAA). NOAA has sponsored the development of a Wahikuli-Honokōwai Watershed Management Plan (WHWMP) (Sustainable Resources Group International, Inc. 2012) for these watersheds as part of the West Maui R2R Initiative. The WHWMP specified proposed projects intended to decrease land-based pollution to the reef, one of which was an engineering analysis and 
development of retrofit designs for a dam (Honokōwai Structure \#8) located along Honokōwai Stream within the Honokōwai watershed.

The University of Hawaii (UH), Water Resources Research Center, completed this analysis using hydrology and sedimentation modeling and developed runoff hydrographs and sedographs for 2-, 10-, 25-, 50-, and 100-year recurrence storms, as well as estimates of trapping efficiency for the existing dam and potential future modifications (Babcock et al. 2014). Due to the availability of these data, the designation of the resources in this area as a priority coral reef, and the limited stream and sedimentation data in other areas of the region, it was decided to use the Honokōwai Stream as a representative example of upland sediment input to the nearshore region for the West Maui RSM follow-up study. Summaries of the stream and upland sediment inputs study, and the nearshore wave-hydrodynamic-sediment transport modeling study, are provided in this RSM Technical Note (RSM-TN).

Stream and Upland Sediment Inputs. The Honokōwai Stream drains approximately 70 percent $(\%)$ of the total area of the Honokōwai Watershed. Honokōwai Structure \#8 (located on Honokōwai Stream) receives runoff from the conservation and agricultural districts of the Honokōwai Watershed. During and following periods of moderate to high rains, Honokōwai Stream flows and carries fine and coarse sediments and other pollutants that are attached to the sediment particles, as well as plant matter and animal waste (Sustainable Resources Group International, Inc. 2012). The Honokōwai stream has had an annual peak discharge range of 120 to 4520 cubic feet per second (cfs), according to U.S. Geological Survey data obtained from 1961 to 2009 (47 records), with an average of $753 \mathrm{cfs}$ ( http://waterdata.usgs.gov). While these streams were once perennial streams, today they are considered ephemeral (Babcock et al. 2014). Honokōwai Dam and its debris basin are located on the main channel 750 feet (ft) inland of Honoapi 'ilani Highway (Sustainable Resources Group International, Inc. 2012). A portion of the pollutants carried in the water, primarily the fine matter, makes it past Honokōwai Structure \#8 and flows to the ocean (Figure 2).

The watershed hydrology was modeled using the Gridded Surface Subsurface Hydrologic Analysis (GSSHA) model (Downer and Ogden 2006) to develop predictions of runoff hydrographs in the Honokōwai Stream for 2-, 10-, 25-, 50-, and 100-year recurrence storms using published rainfall data (Figure 3). The routing of runoff through the basin and the retention of sediment in the basin was modeled using the Environmental Protection Agency's Storm Water Management Model (SWMM) (Babcock et al. 2014). The results from the GSSHA and SWMM models were used to develop time-series streamflow inputs to CMS-Flow, as well as a range of sediment point source rates into the PTM. The intent of the RSM modeling was to demonstrate the results of a fairly typical rainfall event. Consequently, the 2-year recurrence interval storm hydrograph was used to develop the CMS-Flow streamflow input time-series, and the associated estimate of sediment mass not retained in the sediment basin during this event was used to develop the rate of sediment released from a point source located at the mouth of the Honokōwai Stream. 


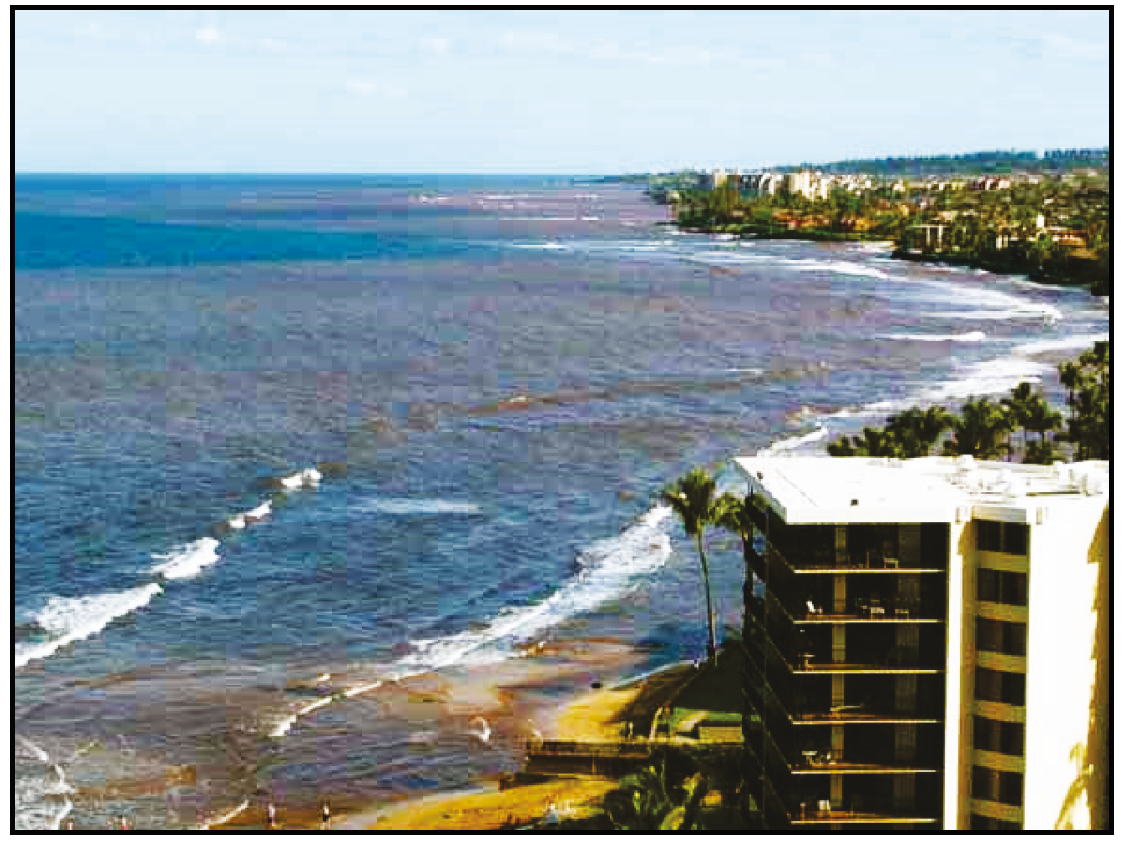

Figure 2. West Maui shoreline looking north near the Honokōwai Stream after significant rains, showing nearshore turbidity of water (January 2015).

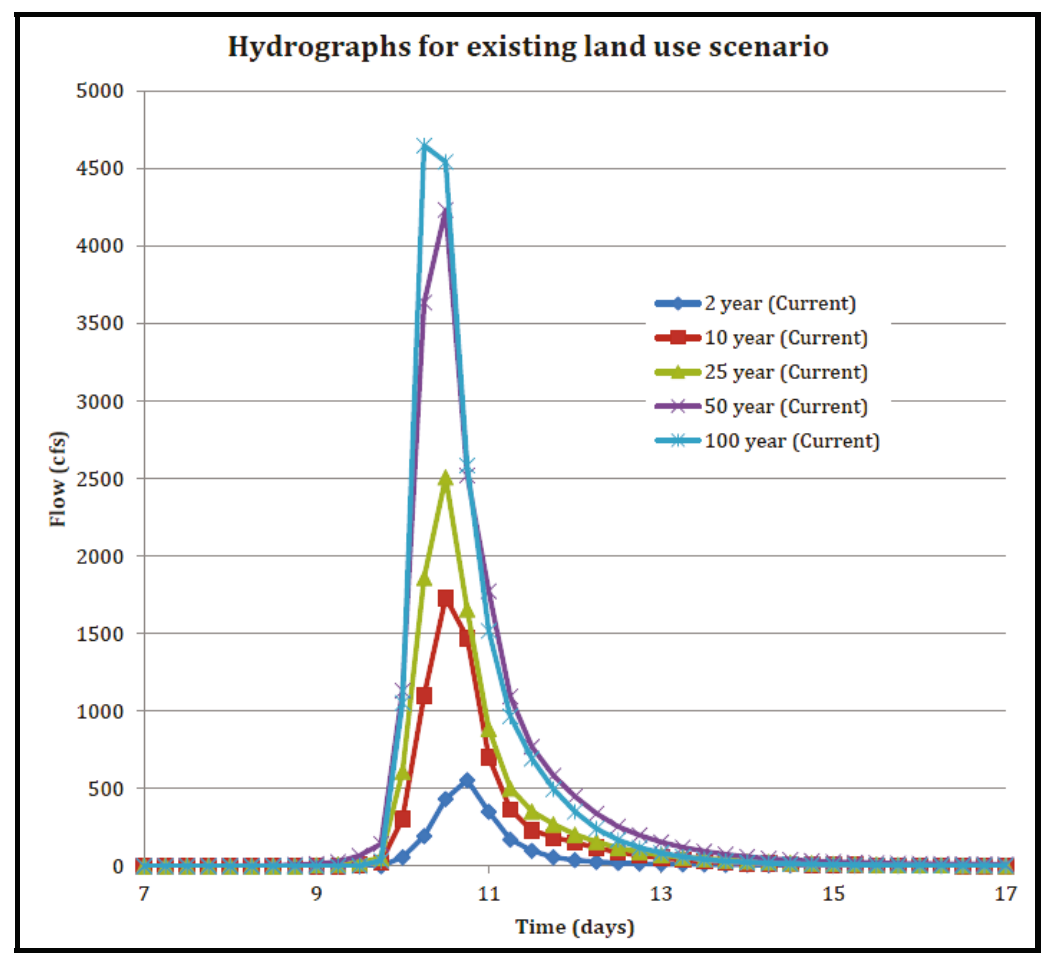

Figure 3. Honokōwai watershed hydrographs for existing land use conditions. Hydrographs superimposed for comparison (Babcock et al. 2014). 
Sediment sampling and grain size analysis were conducted as part of the UH study at three upland locations in West Maui, each with varying composition of gravel, sand, medium silt, fine silt, and clay. It is noted by Babcock et al. (2014) that the majority of gravel and sand is transported as bedload and therefore is likely to be retained in the sedimentation basin, leaving silt and clay to be transported to the stream mouth and ocean as suspended load. Also noted in the Babcock report, "fine silts and clays play a disproportionate role in reducing water quality" and "the silt and clay fractions are most likely to significantly influence the resource we are trying to protect in west Maui." In light of this information, a grain size of 0.01 millimeter (mm) was used as the median grain size within PTM, which applies a Gaussian particle size distribution. This grain size was intended to represent sediment inputs of medium silt $(0.025$ $\mathrm{mm})$ to small silt $(0.007 \mathrm{~mm})$. The $0.01 \mathrm{~mm}$ grain size is the minimum recommended value (Podoski et al. 2016; MacDonald et al. 2006) that can be used in the PTM model to track cohesive sediments (i.e., fines and clay particles).

NUMERICAL MODELING: The majority of the wave and circulation model setup, including ocean bathymetry, boundary conditions, model calibration, and testing, was completed as part of Hawaii RSM in FY14 (Podoski et al. 2016). This investigation into terrestrial stream sediment inputs to the West Maui nearshore significantly leveraged that completed work. The existing CMS-Wave model child grid was used as is while the CMS-Flow child grid was modified to represent flow input from Honokōwai Stream by adding a stream input boundary at the mouth of the stream (Figure 4).

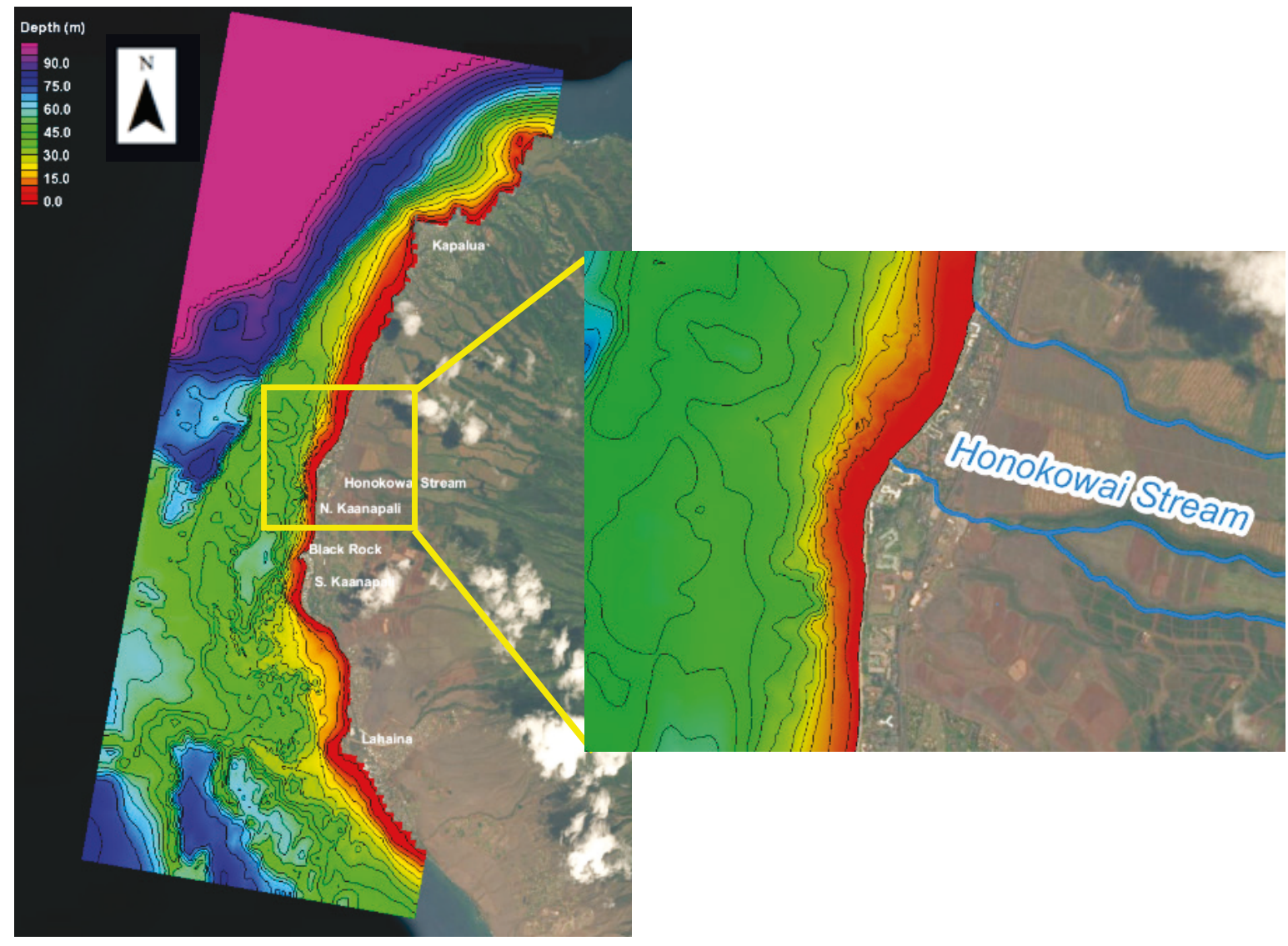

Figure 4. Modified CMS-Flow child grid (left) and zoomed-in view of the added Honokōwai Stream input boundary at the mouth of the stream (right). 
Boundary conditions for water level, wind, and waves were developed for the previous RSM study over two long-term simulations: January-December 2003 (12 months) and September 2009-December 2010 (16 months). This provided a large database of boundary input conditions and without-stream wave and current fields for the West Maui region. Steering runs (coupled wave and circulation model simulations) for several different wave and wind conditions were completed using portions of these same boundary conditions but with the modified CMS-Flow boundary condition, which included point source flow inputs based on the 2-year recurrence interval from the Honokōwai Stream study.

These new simulations were compared with previous simulations. The comparison indicated that the velocity generated from the 2-year recurrence stream flow into the ocean (based on a peak flow of approximately $555 \mathrm{cfs}$ across a $\sim 65 \mathrm{ft}$ wide outfall) was insignificant in comparison to nearshore current velocities driven by waves, bathymetry, and tides. The stream outflow did not create a sufficently strong $e b b$ jet that could modify the observed nearshore currents without the stream input (Figure 5). This is not surprising considering the relatively small flow rate generated by this perennial stream. However, the introduction of fresh water from the stream into the ocean may cause additional vertical mixing in the water column because of density and salinity differences in the fresh vs. salt water. Such a mixing phenomenon can signficantly alter sediment transport patterns, especially transport patterns of fine sediments including muds and clays. Resolving this process would require the use of a 3D circulation model with cohesive sediment transport modeling capabilities, which was beyond the scope of this conceptual effort to apply the CMS and PTM numerical models at an island scale to investigate the transport and fate of inland sediment inputs to the nearshore littoral environment. Comprehensive 3D modeling of the region with cohesive sediment transport, temperature and salinity effects, and pre- and post-storm sedimentation data at coral reefs is recommended.

The PTM was used in combination with the updated CMS-Flow hydrodynamics to evaluate sediment transport pathways of the terrestrial sediment. Sediment flow rates and median grain size input data for the model were developed using the UH study results, and a single point source was used at the stream mouth to simulate sediment entrained in the incoming stream flow. The results of one PTM simulation that was generated with a CMS-Wave and CMS-Flow steering run that used wave, water level, and wind boundary conditions over a 12-day period for 18-30 November 2003 are presented herein as a representative example. 


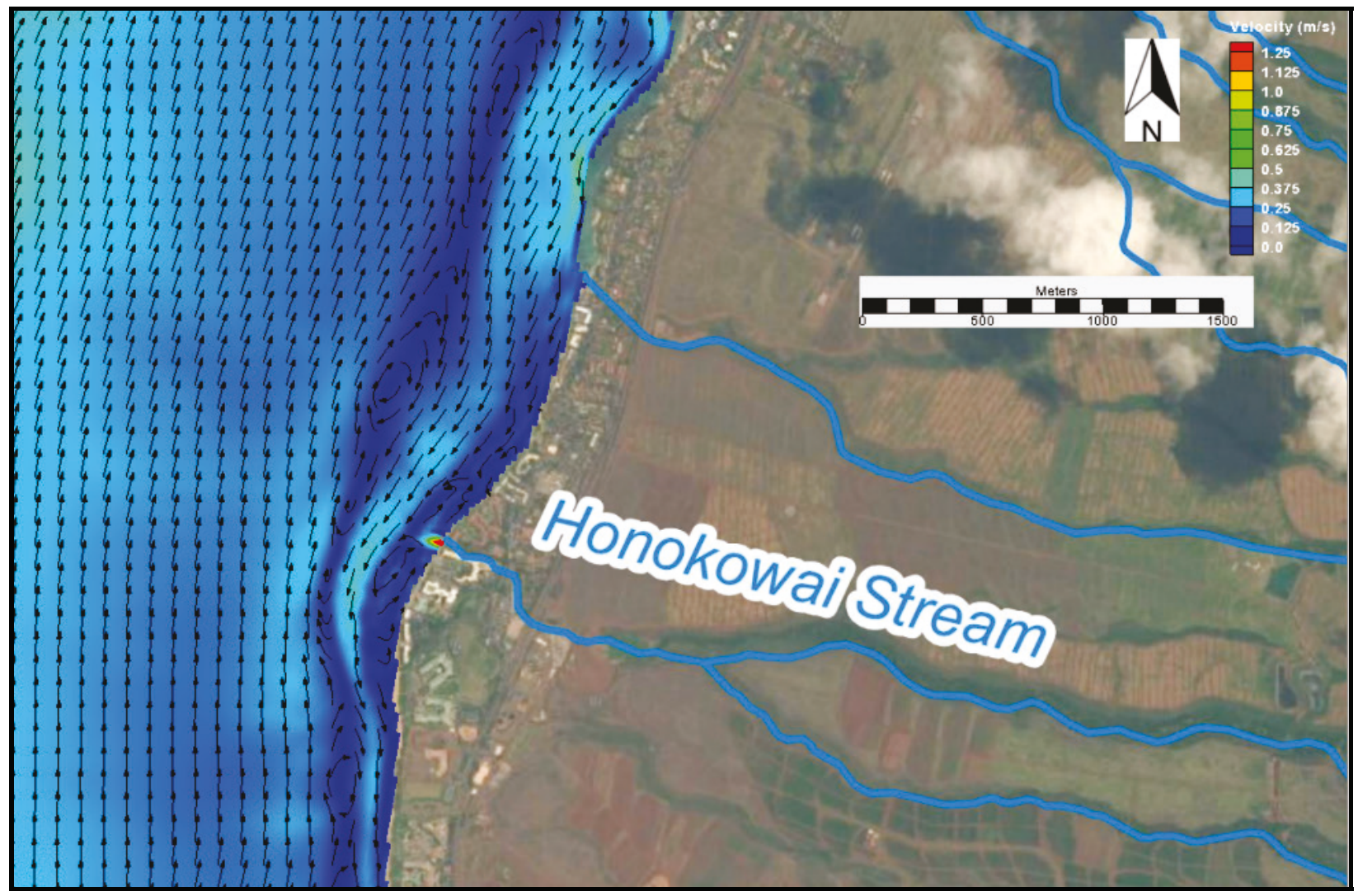

Figure 5. Calculated flow field at the mouth of the Honokōwai Stream during a 2-year recurrence interval rain event (typical).

The U.S. Army Engineer Research and Development Center (ERDC) Wave Information Study (WIS) hindcast Station 82516, located in deep water north of Maui, provided wave and wind input to the CMS models. As shown in Figure 6, wave conditions during November 2003 (shown in the upper panel) were relatively mild tradewind seas (significant wave height, $\mathrm{Hs}<13.2 \mathrm{ft}$ ) for most of November but increased due to north swell energy beginning on 19 November 2003 to a peak significant wave height of $18.7 \mathrm{ft}$ coming from north-northeast on 22 November 2003 (which corresponds to a 1-year recurrence interval wave event at this station) before returning to below $13.2 \mathrm{ft}$ a few days later. Winds (shown in the lower panel of Figure 7) were mostly in the typical tradewind range of 8 to 25 knots from the northeast-through-east quadrant until 18 November, then shifted to the north before swinging clockwise to west and dropping as low as 4 knots on 24 and 28 November 2003. NOAA water level Station 1615680 located along the north Maui coast in Kahului provided partial water level input to the CMS models. During the PTM simulation for 18-30 November 2003, the water level went from neap to spring tide, with a maximum tide differential of approximately $3.6 \mathrm{ft}$. 
ERDC/TN RSM-18-8

October 2018

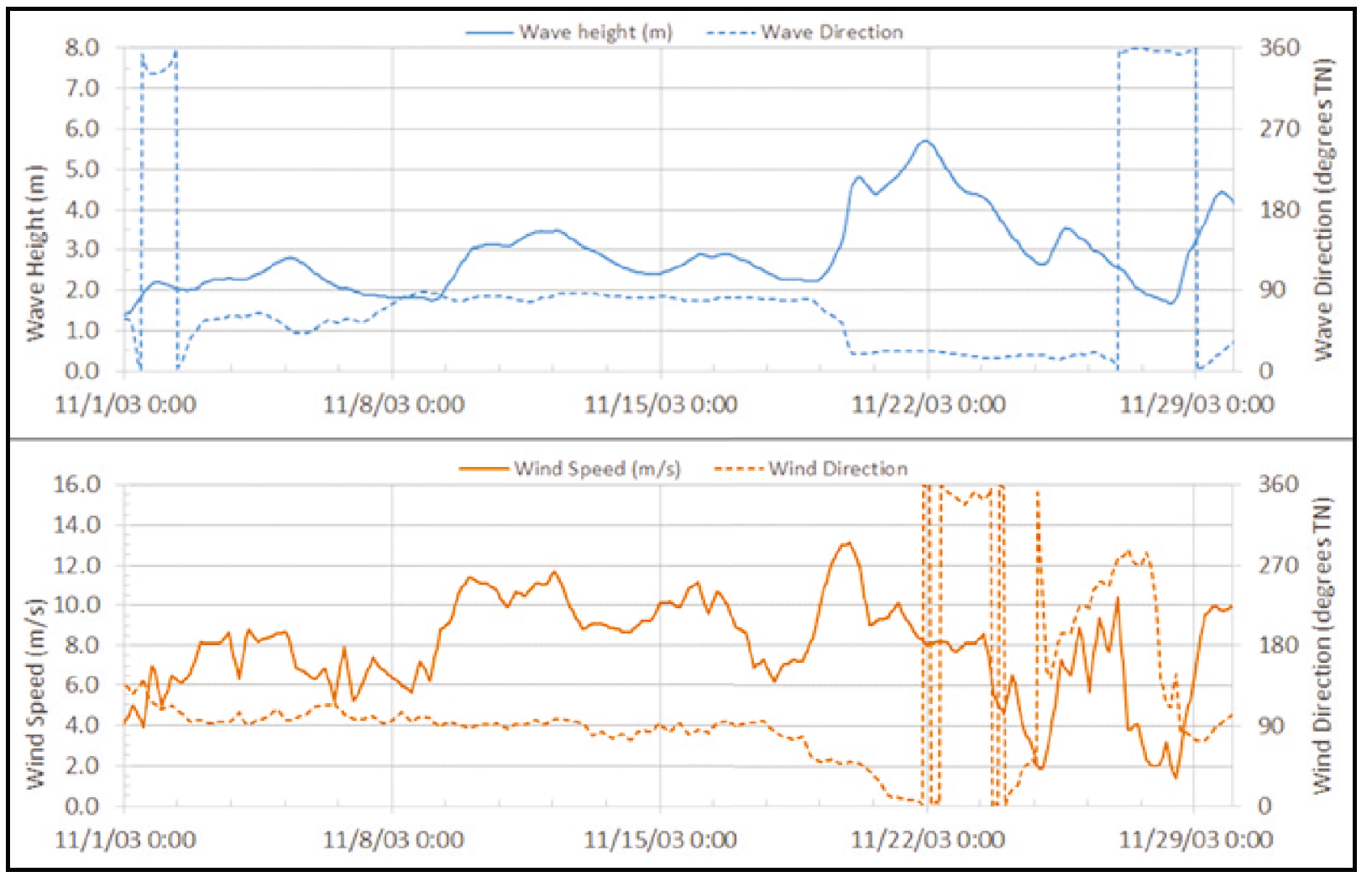

Figure 6. Wave height (meters) and direction, and wind speed (meters per second) and direction, at WIS Station 82516 during November 2003.

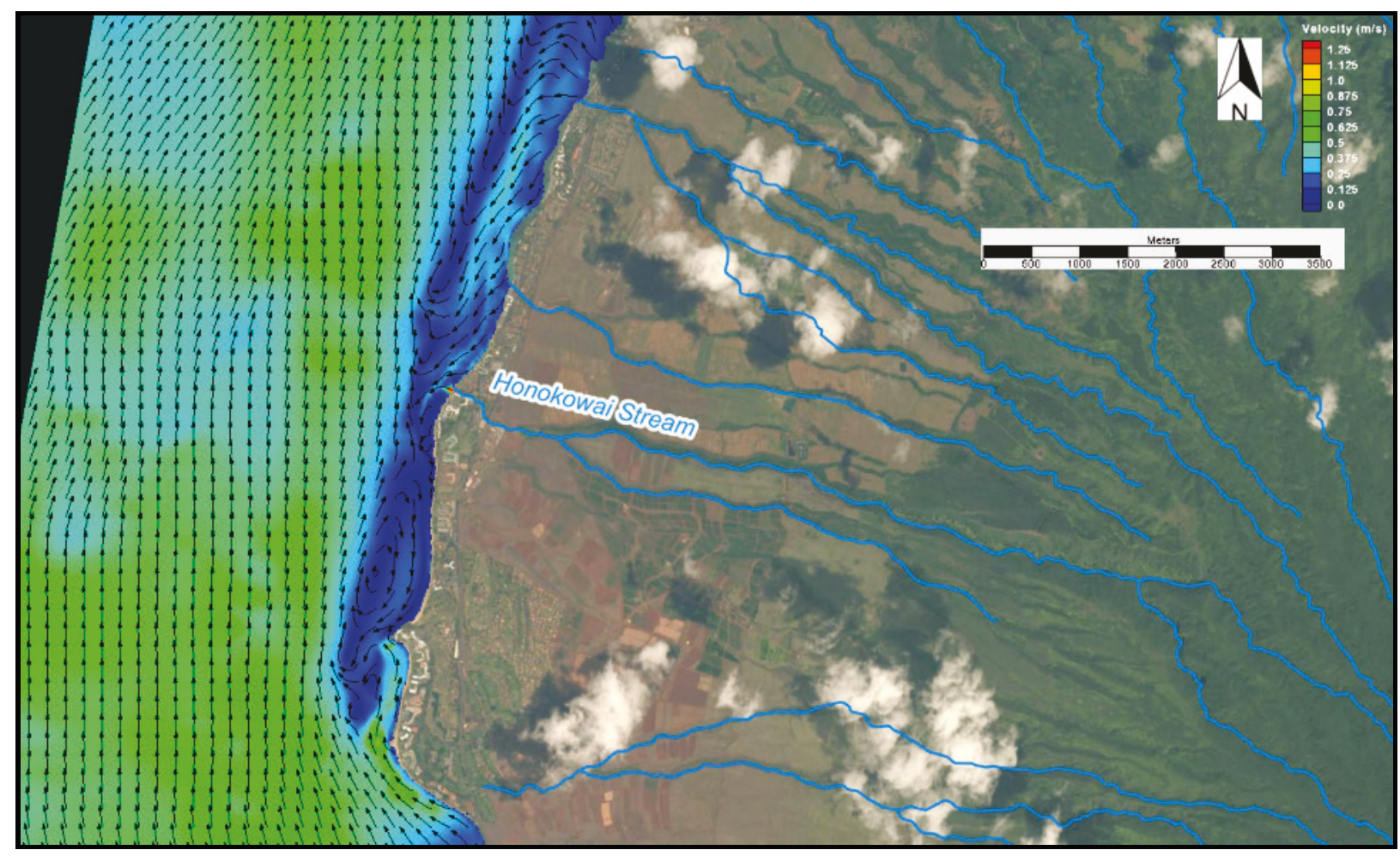

Figure 7. Flow field on 14 November 2003 at 18:00 showing the Honokōwai and the Ka'anapali regions of West Maui. 
As noted in the previous investigations of this area (Podoski et al. 2016; Storlazzi et al. 2008), circulation in the region is influenced by wave direction, winds, bathymetry (including shallow nearshore reefs), tidal currents, and sheltering due to shoreline orientation and headlands. There are two distinct circulation zones along the West Maui coastline, which are clearly shown in the CMS-Flow velocity fields of Figure 7. Currents in the deeper offshore areas are predominantly directed to the north during 1-19 November 2003 (trade wind sea conditions), with nearshore currents showing greater variability in direction and magnitude and often in opposition with the offshore (directed to the south). Also evident during this period is a clockwise eddy that forms in

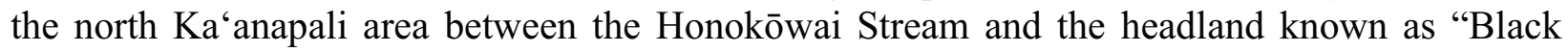
Rock," which divides Ka'anapali into north and south (Figure 7). After 19 November 2003 (during variable wind and north swell conditions), the offshore current changes to predominantly southward-directed while the nearshore current continues to vary frequently in direction. The nearshore current is predominantly northward-directed after 24 November 2003 (when wind direction originates from south and west) forming a counter-clockwise eddy in the north $\mathrm{Ka}$ 'anapali region south of the stream (Figure 8). This reverse flow and eddy have been discussed by Podoski et al. (2016) and by Storlazzi et al. (2008).

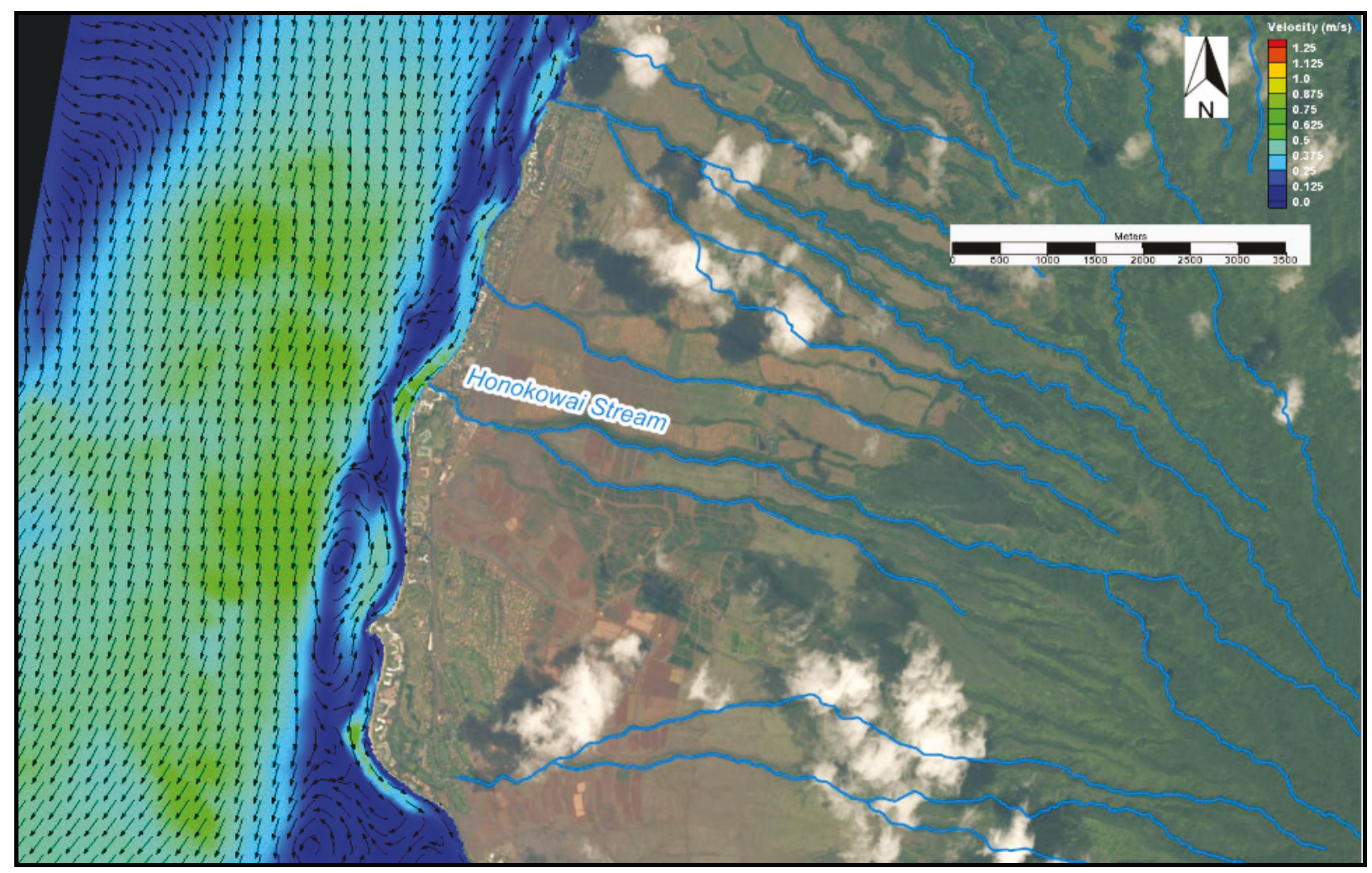

Figure 8. Flow field on 26 November 2003 at 21:00 showing the Honokōwai and the Ka'anapali regions of West Maui.

PTM simulations were conducted with the 2-year recurrence stream flow boundary and sediment inputs during 18-30 November 2003. As previously noted, the circulation pattern in the region during this time was dominated by southward-directed offshore flow and a variable nearshore current, with a counter-clockwise eddy to the south of Honokōwai Stream toward the end of the month. At the beginning of the simulation when both nearshore and offshore currents are 
directed toward the south, sediment from the source is carried south from the stream along the nearshore then swept into the offshore current and dissipates rapidly (within a few hours). Later in the simulation (after 24 November when wind direction shifts and nearshore current is predominantly toward the north), sediment is again directed south from the stream along the nearshore; however, the sediment becomes entrained in the counterclockwise eddy along the $\mathrm{Ka}$ 'anapali region. This transport pattern is illustrated in a snapshot of the PTM simulation shown in Figure 9a. These sediment particles remain in the nearshore eddy for a duration of approximately 3 to 4 days, during the period of 24-28 November 2003, gradually migrating to the south and eventually moving into the offshore current where they are dissipated.

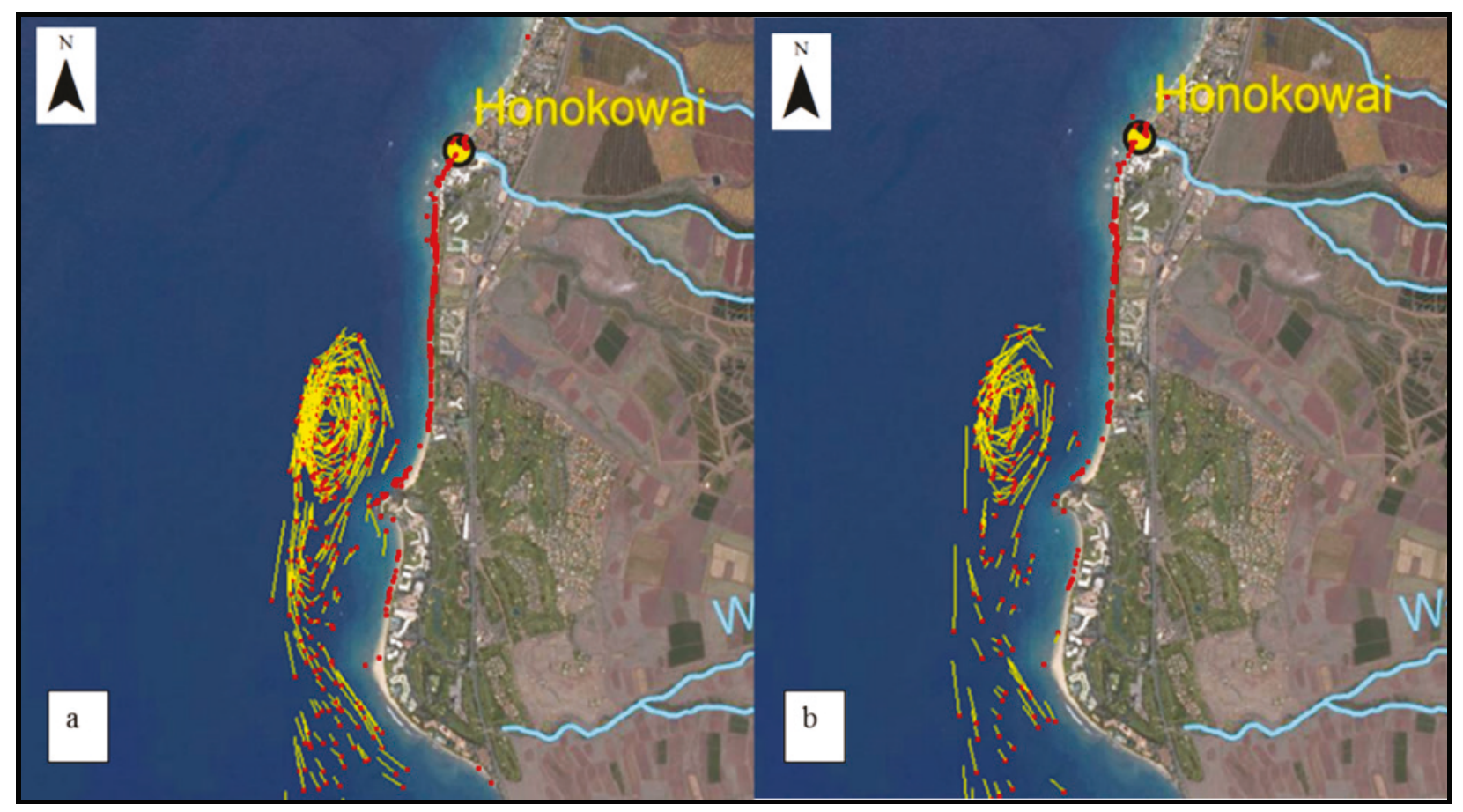

Figures 9a and 9b. Snapshot from November 2003 PTM simulation with sediment circulating in a nearshore eddy south of the Honokōwai Stream. Red circles are sediment particles; yellow lines are tails showing sediment movement in the previous 30 minutes. Figure 9a (left) represents existing sediment input; Figure 9b (right) represents reduced sediment input after recommended modifications to the existing sediment retention structure.

Another PTM simulation was completed over the same time period but with sediment input at the stream mouth reduced by approximately $60 \%$. This was intended to conceptually represent the reduction in sediment flow that is anticipated if the recommended modification scenario to Honokōwai Structure \#8 from the UH study were implemented under existing land use conditions. The results of the simulation indicate that sediment would still follow the same general circulation patterns as the existing condition but would result in a lesser density of particles in the water column (Figure 9b). This similar circulation pattern is likely due to the fine grain size of the material that is entrained in the water column being transported as suspended load rather than bedload. 
SUMMARY AND CONCLUSIONS: This study was conducted as a conceptual effort, at an island scale opposed to the extensive watershed scale within the continental United States, to apply the CMS and PTM numerical models to investigate the transport and fate of inland sediment inputs to the nearshore littoral environment. Because inland sediment input to the nearshore littoral environment is a coral reef stressor, the CMS and PTM were applied to better understand the circulation patterns along the coast that influence the transport and fate of the Honokowai stream sediment inputs within the nearshore littoral environment of the West Maui, HI, region. Further comprehensive 3D modeling of the region with cohesive sediment transport, temperature and salinity effects, and pre- and post-storm sedimentation data at coral reefs is recommended.

This continuation of previous RSM work in the West Maui region, in combination with existing data being developed as part of a larger watershed initiative in the area, has enabled a preliminary evaluation of the potential impact of terrestrial sediments entering a nearshore area with valuable coral resources. Wave and circulation modeling (augmented by stream flow input) paired with sediment transport pathway visualizations has given further insight into the fate of fine sediment released from the Honokōwai Stream during large rain events.

The representative example PTM simulation for 18-30 November 2003 showed that sediment from Honokōwai Stream was directed primarily southward toward the Ka'anapali area. Other modeling conducted to simulate various wind and wave conditions (e.g., tradewind seas, south swell, and Kona wind conditions) showed a similar transport regime, with sediments from this stream directed primarily southward by the dominant nearshore current at the stream. The results shown here (in addition to other simulations) also indicate that when opposing offshore and nearshore current directions occur along the West Maui shoreline, circulation eddies form in the areas just offshore of the north and south $\mathrm{Ka}^{6}$ anapali littoral cells. Fine sediments being transported from the stream as suspended load that are entrained in these eddies may remain in the nearshore for several days. This is consistent with observations along the West Maui shoreline of cloudy water for days and sometimes weeks after a heavy rain. The longer residence time of sediments in the nearshore may cause a portion of the sediment to fall out of suspension and settle on the coral reefs in this region.

These results are indicative of just one of several streams in the West Maui region. Conditions at other stream mouths with varying nearshore bathymetry and exposure to waves may produce different local circulation patterns, transport pathways, and associated effects on nearby coral resources. Both the flow rates and current velocities for Honokōwai Stream and other streams in the region are generally small. However, the Honokōwai Stream delivers a significant amount of fine sediment to the nearshore area of interest over a 2 -year rainfall event. The combined upland terrestrial runoff into streams along the entire watershed, and the resulting transport of fine and cohesive sediments into the nearshore from multiple sources, clearly significantly impacts water quality along the West Maui coast. Further comprehensive 3D modeling of the region with cohesive sediment transport, temperature and salinity effects, and pre- and post-storm sedimentation data at coral reefs is recommended. Such a study could shed further light onto exactly which sources contribute the most to nearshore sedimentation in particular areas of interest. A 3D study would assist in quantifying which coral resource areas are most affected when this sediment resides in the nearshore of the West Maui region over short and long time periods. The additional study would also assist in quantifying impacts of routine (typical) and extreme rain events on the health of coral reefs. 
POINTS OF CONTACT: This effort was supported by the U.S. Army Corps of Engineers (USACE), National Regional Sediment Management (RSM) Program, and the Hawaii RSM Program, and was conducted by Jessica Podoski and Lauren Molina, U.S. Army Engineer District, Honolulu (POH); and Zeki Demirbilek and Lihwa Lin, U.S. Army Engineer Research and Development Center (ERDC), Coastal and Hydraulics Laboratory (CHL). This RSM Technical Note (RSM-TN) was written by Jessica Podoski with contributions from the Hawaii RSM Product Delivery Team and the ERDC modeling team. Additional information pertaining to Hawaii RSM can be found at http://rsm.usace.army.mil/Hawaii and to the USACE National RSM Program at http://rsm.usace.army.mil.

Questions regarding this RSM-TN and the National RSM Program may be addressed to the following:

Jessica H. Podoski Jessica.H.Podoski@usace.army.mil

(POH RSM Specialist)

Linda S. Lillycrop Linda.S.Lillycrop@usace.army.mil

(USACE National RSM

Program Manager)

This ERDC/TN RSM-18-8 should be cited as follows:

Podoski, J. H., L. Molina, Z. Demirbilek, and L. Lin. 2018. Hawaii regional sediment management: West Maui region; Nearshore sedimentation at Honokōwai Stream. ERDC/TN RSM-18-8. Vicksburg, MS: U.S. Army Engineer Research and Development Center. http://dx.doi.org/10.21079/11681/29708

\section{REFERENCES}

Babcock, R., S. Bateni, O. Francis, K. Falinski, J. Nielson, B. Harada, K. Smith, and Y. Li. 2014. Sediment Retention at Honokōwai Structure \#8; Wahikuli-Honokōwai Priority Site. Prepared for State of Hawaii, Department of Land and Natural Resources, Division of Aquatic Resources. Honolulu. HI: University of Hawaii, Water Resources Research Center, NOAA Grant Number: NA11NOS4820006. https://dlnr.hawaii.gov/coralreefs/files/2014/12/Honokowai_DARNOAA_report.pdf.

Demirbilek, Z., and J. D. Rosati. 2011. Verification and Validation of the Coastal Modeling System: Report 1; Summary Report. ERDC/CHL TR-11-10. Vicksburg, MS: U.S. Army Engineer Research and Development Center. http://acwc.sdp.sirsi.net/client/search/asset/1005704.

Downer, C. W., and F. L. Ogden. 2006. Gridded Surface Subsurface Hydrologic Analysis (GSSHA) User's Manual: Version 1.43 for Watershed Modeling System 6.1. ERDC/CHL SR-06-1. Vicksburg, MS: U.S. Army Engineer Research and Development Center. http://acwc.sdp.sirsi.net/client/en_US/search/asset/1000104.

Lin, L., Z. Demirbilek, R. Thomas, and J. Rosati. 2011. Verification and Validation of the Coastal Modeling System: Report 2; CMS-Wave. ERDC/CHL TR-11-10. Vicksburg, MS: U.S. Army Engineer Research and Development Center. http://acwc.sdp.sirsi.net/client/search/asset/1005705.

MacDonald, N. J., M. H. Davies, A. K. Zundel, J. D. Howlett, Z. Demirbilek, J. Z. Gailani, T. C. Lackey, and J. Smith. 2006. PTM: Particle Tracking Model: Report 1; Model Theory, Implementation, and Example Applications. ERDC/CHL TR-06-20. Vicksburg, MS: U.S. Army Engineer Research and Development Center. http://acwc.sdp.sirsi.net/client/search/asset/1000777.

Pinniak, G. 2004. Sediment Impacts on Reef Corals in Maui, Hawaii. http://soundwaves.usgs.gov/2004/11/. 
Podoski, J. H., T. D. Smith, Z. Demirbilek, L. Lin, and L. S. Lillycrop. 2016. Hawaii Regional Sediment Management (RSM): Regional Sediment Budget for the West Maui Region. ERDC/CHL TR-16-5. Vicksburg, MS: U.S. Army Engineer Research and Development Center. http://acwc.sdp.sirsi.net/client/search/asset/1050229.

Sanchez, A., W. Wu, T. M. Beck, H. Li, J. Rosati, R. Thomas, J. D. Rosati, Z. Demirbilek, M. Brown, and C. Reed. 2011a. Verification and Validation of the Coastal Modelling System: Report 3; CMS-Flow, Hydrodynamics. ERDC/CHL TR-11-10. Vicksburg, MS: U.S. Army Engineer Research and Development Center. http://acwc.sdp.sirsi.net/client/search/asset/1005706.

Sanchez, A., W. Wu, T. M. Beck, H. Li, J. D. Rosati, Z. Demirbilek, and M. Brown. 2011b. Verification and Validation of the Coastal Modelling System: Report 4; CMS-Flow, Sediment Transport and Morphology Change. ERDC/CHL TR-11-10. Vicksburg, MS: U.S. Army Engineer Research and Development Center. http://acwc.sdp.sirsi.net/client/search/asset/1005707.

Storlazzi, C. D., and M. E. Field. 2008. Wind, Waves, Tides, and the Resulting Flow Patterns and Fluxes of Water, Sediment, and Coral Larvae off West Maui, Hawaii. Open-File Report 2008-1215. Santa Cruz, CA: U.S. Department of the Interior, U.S. Geological Survey, Pacific Coastal and Marine Science Center. http://pubs.usgs.gov/of/2008/1215.

Sustainable Resources Group International, Inc. 2012. Wahikuli-Honokōwai Watershed Management Plan: Volume 1, Watershed Characterization; Volume 2, Strategies and Implementation. Prepared for National Oceanic and Atmospheric Administration, Coral Reef Conservation Program, Silver Spring, MD. http://coralreef.noaa.gov/welcome.html. Kailua, HI: Sustainable Resources Group International, Inc. http://www.srgii.com.

NOTE: The contents of this technical note are not to be used for advertising, publication, or promotional purposes.

Citation of trade names does not constitute an official endorsement or approval of the use of such products. 